\title{
Cuando la nube no es simplemente una metáfora
}

\author{
Susana Morales ${ }^{1}$ y Graciela Natansohn ${ }^{2}$
}

Recibido: 28/05/2021; Aceptado: 31/05/2021

Cómo citar: Morales, S. y Natansohn, G. (2021) Cuando la nube no es simplemente una metáfora. Revista Hipertextos, 9 (15), 207-210. DOI: https:// doi.org/10.24215/23143924e037

En las páginas que siguen, proponemos analizar una iniciativa lanzada recientemente por el gobierno argentino, respecto a la creación de una Nube Pública en Gobierno.

La expresión de "nube" en realidad es una metáfora muy difunda, que alude a un lugar donde se almacena la información que luego se recupera a través de Internet (ejemplos comunes son Google Drive, OneDrive de Microsoft o Icloud de Apple, aunque es mucho más que eso: todas las interacciones que tenemos con Internet se almacenan, las cosas que compartimos, los consumos, lo correos electrónicos, etc.). Pero muchas personas no se imaginan qué sería ese espacio: la nube. Es un conjunto (miles y hasta millones) de computadoras o lotes de almacenamiento, con gran capacidad. Estas granjas de servidores, como han sido llamadas, han dado lugar a la idea de cómputo en la nube, que es un concepto actual. En general, las empresas $\mathrm{u}$ organizaciones tradicionalmente han desarrollado sus sistemas de computación y alojado los datos que generan en sus propias computadoras o servidores. Por ejemplo, compañías aseguradoras, o bancos, gobiernos, etc. Pero eso requiere una gran inversión en tecnología, mantenimiento y en software. Por eso ahora, actualmente y cada vez más, están adoptando lo que se llama cómputo en la nube, es decir "tercerizando" en cierto modo esa tarea. Las principales proveedoras de este tipo de servicios son Microsoft, Amazon y Google.

Lo que está haciendo el gobierno argentino con esta iniciativa es crear una nube (y los servicios asociados) para el sector de gobierno, para que, por ejemplo, en lugar de almacenar los datos en nubes de empresas de tecnología con sede en territorio extranjero, se haga en el país.

Una cuestión que hay que tener en cuenta para entender la propuesta del gobierno es el marco en que se inscribe esta iniciativa, el Plan Conectar 2020-2023, que tiene 4 ejes: el desarrollo y construcción del satélite ARSAT-SG1, la actualización y ampliación de la Red Federal de Fibra Óptica, la actualización de equipamiento para la Televisión Digital Abierta, y la ampliación del Centro Nacional de Datos de ARSAT. Este último (ubicado en la provincia de Buenos Aires)

1 Docente investigadora de la UNC en temas de tecnologías digitales, apropiación y vida cotidiana. Contacto susanamorales@unc.edu.ar

2 Periodista e investigadora en Comunicación en la Universidad Federal da Bahia, Brasil, en tecnologías digitales con perspectiva feminista. Contacto: graciela@ufba.br 
está asociado a los servicios de "nube" (almacenamiento y servicios de cómputo), con lo cual se pretende "tener soberanía política sobre nuestros datos", según la propia definición del gobierno. Por lo cual, se espera que los datos generados en nuestro país, en lugar de quedar almacenados en servidores de empresas de países extranjeros, queden en nuestro país, en el Centro Nacional de Datos.

A los efectos de involucrar en esta iniciativa a diversos actores sociales, el gobierno abrió una Consulta Pública para conocer y receptar propuestas representativas que expresen diferentes intereses.

Entendemos que, como nunca, los conocimientos científico-tecnológicos deben ponerse a disposición de la ciudadanía para que, de manera informada, las personas podamos participar en la toma de decisiones, sea individual u organizadamente, en nuestras prácticas cotidianas o en las políticas públicas. Es decir, no se puede dejar solamente en manos del mercado tecnológico o los grupos de expertos informáticos la dirección que toma la sociedad en estas cuestiones, porque afectan cada vez más nuestras vidas, nuestras democracias y nuestros derechos. Es por ello que desde la universidad pública hemos generado una serie de conversaciones sobre la iniciativa de la nube híbrida en gobierno, y hemos elaborado un documento de análisis y propuestas que se puede consultar en línea, tratando de hacer un aporte al diseño de esta política pública.

Así, durante los días 29, 30 y 31 de Marzo, a través del Ciclo de Conversaciones en Red V, organizado por GATEC (Grupo de Investigación Apropiación de Tecnologías digitales y Comunicación-UNC) y GIG@ (Grupo de Pesquisa em Género, tecnologias digitais e culturaUFBA, Brasil), nos propusimos generar un escenario de debate en torno a este tema. Denominamos a este Ciclo de Conversaciones como "Soberanía tecnológica ¿que implica y cómo alcanzarla? Debates en torno a la creación de la Nube Pública Nacional", y por ello una buena parte de las discusiones se dieron alrededor de esta idea. Como fruto de esos días de intercambio de opiniones, produjimos un documento elaborado por 18 académicos y activistas que participaron del Ciclo, que contó con la adhesión de 18 instituciones académicas y más de 100 firmas individuales, y fue elevado como propuesta de este grupo de trabajo ante la Secretaría de Innovación Pública. El documento completo puede leerse en: https://nhg2021.sutty.nl//

A lo largo de esas jornadas, debatimos diferentes aspectos respecto de la propuesta del gobierno, partiendo de la base que la misma es una iniciativa necesaria y que trasciende los territorios nacionales, por lo que se enmarca en un asunto de importancia geopolítica regional. Resulta valioso que el Estado argentino haya instalado este tema en la agenda pública y lo haya puesto a consideración de la sociedad a través de consulta pública. Este proyecto puede servir de impulso y referencia para el resto de los países de la región, cuando las condiciones políticas avalen la deseada integración y cooperación regional en términos más justos y solidarios

En este sentido, en el documento que produjimos, postulamos que "la idea de soberanía tecnológica del proyecto de ARSAT es una condición necesaria pero insuficiente para abordar los múltiples desafíos que las tecnologías digitales plantean". Si bien se reconoce que hay diversidad de planos en los cuales es preciso tener un horizonte de soberanía, desde este espacio de trabajo entendemos que se trata de reconocer "la capacidad del Estado de decidir sobre la adquisición, creación y uso de tecnologías que mejor se adecúen a los intereses nacionales". Esta capacidad se expresa en las políticas públicas.

Asimismo, consideramos que es preciso comprender la complejidad de fenómenos o dimensiones que atraviesan una política orientada a la soberanía, en este caso tecnológica, dado 
que en general existen múltiples condicionantes que permitan alcanzarla plenamente. No obstante, es posible pensar en el sentido de ampliar el horizonte de autonomía en cuestiones de tecnologías, que incorpore además de la mirada del Estado, la de las organizaciones sociales y del sector académico.

La nube híbrida es el primer paso hacia la soberanía o autonomía de los datos generados en el sector de gobierno, en las diferentes instancias nacional, provincial y municipales. Esta iniciativa tiene tres ventajas u objetivos importantes: por un lado, porque se trata de retener en nuestro país información (tanto referida a personas como acciones de gobierno, o producción científica, etc.) que se ha vuelto un recurso estratégico en términos incluso económicos. El acceso a datos es la clave para predecir comportamientos, inducir pautas de consumo, opiniones, etc. Por otro lado, porque el almacenamiento de los datos en servidores de empresas extranjeras, se contratan en dólares, por los cuales el país tiene que pagar. Si al menos se puede ahorrar lo que gasta el propio Estado en este momento por servidores en el extranjero, ya es un avance. Y, por último, porque si el Estado centraliza y articula la propia información que genera, sea sobre la ciudadanía y sobre los procesos económicos, sociales, educativos, de salud, etc., está en condiciones ventajosas de diseñar mejores políticas públicas para el desarrollo integral del país.

Sin embargo, y considerando un espectro más amplio de incumbencias en torno a la soberanía/autonomía tecnológica, se reconoce la necesidad de que sea el Estado quien asuma la responsabilidad de proveer reglas antimonopólicas y de control que permitan evitar la concentración, como ocurre actualmente con la provisión de Internet, por ejemplo.

Otro aspecto interesante que discutimos a lo largo de esos días de conversación tiene que ver con las características y denominación que se propone para la Nube Híbrida en Gobierno.

Estas denominaciones de nube pública, privada e híbrida son engañosas. Parecieran hacer referencia a la propiedad de la "nube", es decir si es pública es porque es del Estado y si es privada es porque es propiedad de una empresa privada. No es así. De manera muy simplificada, podría decirse que nube pública significa que los servicios de nube (infraestructura de almacenamiento o software) que una entidad contrata, comparten el alojamiento y servicios de cómputo con otras entidades. Y nube privada es cuando una organización contrata (o los posee en sus propias instalaciones) servidores exclusivos. La nube híbrida es una tercera alternativa donde las organizaciones conservan en servidores exclusivos la información que consideran más sensible, en combinación con una nube pública, y esto es lo más importante: que pueden operar en ambas según los requerimientos.

De manera que la propuesta del gobierno se sitúa en torno a esta última alternativa de nube híbrida, pero a ser adoptada por el sector estatal. En este sentido, hubo consenso entre quienes debatimos en el marco del Ciclo de Conversaciones en Red, de considerar ampliar los actores que podrían beneficiarse de esta iniciativa, para permitir tanto al sector sin fines de lucro, o incluso al sector privado el uso de esta infraestructura. Además, se planteó que la denominación que finalmente se adopte, refiera a la idea de una Nube de Gestión Estatal.

De todos modos, el planteo no es de una competencia entre lo público y lo privado, sino una articulación donde el Estado fije las reglas de funcionamiento, el marco regulatorio, el poder de fiscalización y sanción, para evitar la concentración y siempre garantizando el interés colectivo. Y el sector privado debe amoldarse a esas reglas de juego, no realizar prácticas abusivas o ilegales. En este sentido, el Estado argentino también va a tener que generar un conjunto de instrumentos legales que acompañen este proceso. 
En términos de infraestructura y recursos científico-humanos, se consideró que nuestro país está preparado para encarar un proceso de desarrollo tecnológico que implique mayor independencia de las grandes empresas de TIC. En este aspecto, Argentina tiene una importante herramienta, que es la empresa ARSAT y su Centro de Datos (donde se alojarán los servidores de almacenamiento de los datos, la "nube"), que ya fue mencionado. La inversión anunciada para actualizar este Centro (que es uno de los más modernos y seguros de Latinoamérica) es de 4.300 millones de pesos (aunque la anunciada inversión inicial aparece como exigua). Argentina también posee una importante capacidad en recursos de profesionales formados, ingenieros e informáticos que hoy, en muchos casos, están trabajando de forma independiente para empresas de tecnología extranjeras, cuyas capacidades pueden ser retenidas en el país.

Lo más importante que aporta la iniciativa de la nube argentina, es la inversión por parte del Estado nacional (con fuertes posibilidades de recuperarla y de evitar la erogación de divisas por compra de esos servicios en el extranjero), en el desarrollo tecnológico orientado a la autonomía, puestos de trabajo y cierta independencia ante algún cambio de las políticas de las empresas que hoy brindan el servicio. 